\title{
A SUCCESSFUL MANAGEMENT OF PREGNANCY WITH LUPUS NEPHRITIS
}

\author{
Kalaivani Kannan ${ }^{1}$, Sharmila Ravishankar ${ }^{2}$
}

1 Professor, Department of Obstetrics and Gynaecology, Government Stanley Medical College. 2Postgraduate, Department of Obstetrics and Gynaecology, Government Stanley Medical College.

\section{ABSTRACT}

SLE is a multiorgan autoimmune disease that affects women of childbearing age. The incidence and prevalence of SLE in pregnancy are 1.4-21.9 and 7.4-159.4 per 100,000 people, respectively. ${ }^{1}$ It is first diagnosed during pregnancy in $10-30 \%$ of the cases. Women with lupus nephritis have a good pregnancy outcome if the disease remains in remission. ${ }^{2}$ Active nephritis is associated with higher incidence of maternal complications compared with women without nephritis. ${ }^{3}$ Foetal death with active maternal nephritis also increased than in those with quiescent nephritis. Renal involvement in SLE may either be in the form of active lupus nephritis at the time of conception or a new-onset LN or a lupus flare, all have potential maternal, perinatal morbidity and mortality. Here a case of pregnancy with active lupus nephritis of new onset had a good maternal and foetal outcome is reported.

\section{KEYWORDS}

Lupus nephritis, Systemic Lupus Erythematosus, Proteinuria, IUGR.

HOW TO CITE THIS ARTICLE: Kannan K, Ravishankar S. A successful management of pregnancy with lupus nephritis. J. Evolution Med. Dent. Sci. 2016;5(66):4756-4758, DOI: 10.14260/jemds/2016/1084

\section{INTRODUCTION}

26 years old primi with 33 weeks gestation presented to our OPD with a history of swelling of both legs of 2 months and skin rashes over the face, abdomen, both legs, breasts, and skin over the back of 15 days duration. There was no history of headache, vomiting, or decreased urine output. She was booked at a private hospital and at 20 weeks all routine investigations were done including GCT was within normal limits. Target USG was done at 22 weeks and 6 days and congenital anomalies ruled out. She was a known case of hypothyroidism on regular treatment. TSH in first trimester was 6.7 and was put on T. Thyroxine 100 microgram. At 24 weeks, she developed swelling of both legs and skin rashes and at 32 weeks skin lesions were erythematous with crusting and scaling and were not itchy started in the breasts, anterior abdominal wall, anterior chest wall, both legs, and lastly involved the face. It was in the malar region over the face. History of fever, insect bite, and recent drug intake were ruled out. There was no history of joint pain. There was no past history suggestive of any connective tissue disorder. All relevant investigations done and preeclampsia ruled out.

The above-mentioned presenting complaints of the patient were suspicious of connective tissue disorder. A thorough clinical examination and relevant investigation were done. The diagnosis of active lupus nephritis of new onset was made as per American College of Rheumatology criteria.

\section{On Examination}

Pt. was anaemic, Hb bilateral, pedal oedema, leg oedema + , Erythematous rashes seen over the legs, breasts, and skin over the abdominal wall with scaling and crusting malar rash + , oral ulcers over the palate seen, which were painless. BP $120 / 70$ mmHg, urine albumin 3+, P/A Ut 28-30 wks. size, FH 148/mt.

Financial or Other, Competing Interest: None.

Submission 12-02-2016, Peer Review 01-08-2016,

Acceptance 09-08-2016, Published 18-08-2016.

Corresponding Author:

Dr. Sharmila Ravishankar,

15-C, Vijayaraghavan Street,

Mahalingapuram, Pollachi,

Coimbatore-642002,

Tamilnadu.

E-mail: drsharnima@gmail.com

DOI: 10.14260/jemds/2016/1084

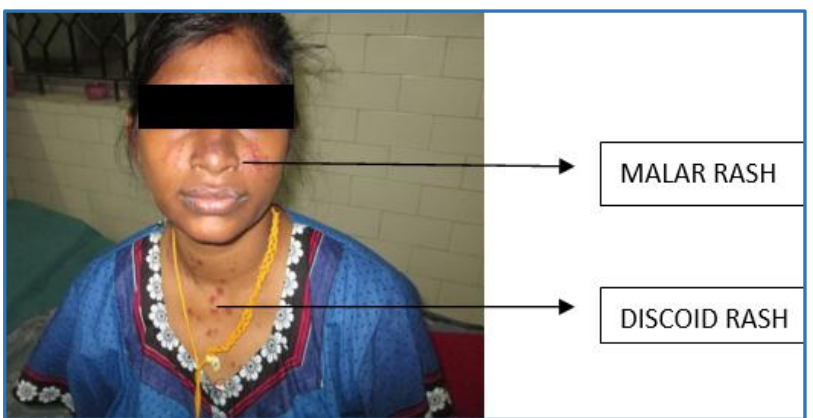

Fig. 1

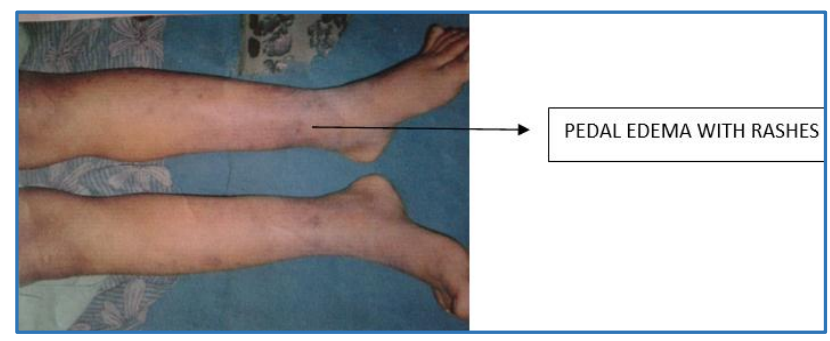

Fig. 2

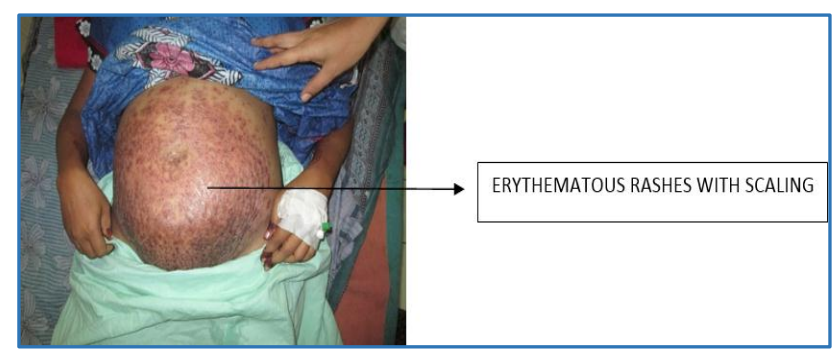

Fig. 3

\section{Investigations}

Investigations showed, Anaemia, with normal platelet count, antinuclear antibody ++++, Anti double stranded DNApositive, Nephrotic range of proteinuria-24 hours urine proteins $-4,688 \mathrm{mg} / 24 \mathrm{hrs}$., hypocomplementaemia $\mathrm{C}_{4}<5.9$ $\mathrm{mg} / \mathrm{dL}(\mathrm{N}-15-50) \mathrm{C}_{3} 30.1 \mathrm{mg} / \mathrm{dL}$ (N-84-168), Sr. creatinine 0.6 $\mathrm{mg} / \mathrm{dL}$, LFT: Total bilirubin $0.5 \mathrm{mg} / \mathrm{dL}$, Total proteins $6.0 \mathrm{~g} / \mathrm{dL}$, Albumin $2.5 \mathrm{~g} / \mathrm{dL}$, Globulin $3.5 \mathrm{~g} / \mathrm{dL}, \mathrm{A} / \mathrm{G}$ ratio 0.7. Normal coagulation profile, VDRL-Non-reactive, Echo-Normal study, admission USG done showed single live foetus with good fetal 
heart. Doppler study - Normal with features s/o mild IUGR. Anticardiolipin antibodies - Negative. Urine routine: Albumin +++ RBC-Nil, Pus cells: plenty, Casts: nil. Peripheral smear showed microcytic hypochromic anaemia with neutrophilia, HbA1c 5.1, Sr. fibrinogen $364 \mathrm{mg} / \mathrm{dL}$, Sr. uric acid 5.1, ESR 78 $\mathrm{mm} / \mathrm{hr}$. TSH-more than $100 \mathrm{micro}$ IU/mL. Lipid profile: Total cholesterol - $287 \mathrm{mg} / \mathrm{dL}$, HDL cholesterol - $28 \mathrm{mg} / \mathrm{dL}$, LDL cholesterol - $163 \mathrm{mg} / \mathrm{dL}$, TGL - $481 \mathrm{mg} / \mathrm{dL}$.

\section{Management with Outcome}

In concordance with nephrologist patient was started on steroids (T. prednisolone $30 \mathrm{mg}$ b.d.), T. Lasix $40 \mathrm{mg}$ 1-1-0 and advised termination of pregnancy if foetus has attained maturity. Dermatologist suggested topical steroid application. $\mathrm{Pt}$. was put on T. hydroxychloroquine and calcium as per rheumatologist opinion. As the patient did not develop hypertension and there was no evidence of foetal compromise and not attained maturity, pregnancy was allowed to progress with careful foetal surveillance. Patient was monitored with repeated investigations and any worsening of proteinuria and renal function looked for.

Repeat renal function test done at 37 weeks showed blood urea $60 \mathrm{mg} / \mathrm{dL}$, sr. creatinine $1.2 \mathrm{mg} / \mathrm{dL}$. USG with Doppler study of UA, MCA arteries at 37 weeks showed SLIUG 33 weeks GA with oligohydramnios, and Doppler study of CPR Reversal in MCA. In view of IUGR with oligohydramnios with CPR reversal with worsening of renal functions, pregnancy was terminated by emergency LSCS and delivered an alive IUGR, LBW GIRL baby of $2.1 \mathrm{~kg}$ with good APGAR.

Even though airway narrowing was anticipated intraoperative period was uneventful. Baby had no skin rashes and was followed up with echo and it was normal with no congenital heart block. Postoperative period was uneventful. Pt. was put on immunosuppressives cyclophosphamide one month after delivery and now she in remission phase of SLE with decreased proteinuric range with one year old well baby.

\section{DISCUSSION}

Criteria of the American Rheumatism Association for Systemic Lupus Erythematosus.

\begin{tabular}{|c|c|}
\hline Criteria & Comments \\
\hline Malar rash & Malar erethema \\
\hline Discoid rash & $\begin{array}{l}\text { Erythematous patches, scaling, } \\
\text { follicular plugging. }\end{array}$ \\
\hline Photo sensitivity & Exposure to UV light causes rash. \\
\hline Oral ulcers & $\begin{array}{l}\text { Usually painless oral ulcers and } \\
\text { Nasopharyngeal Ulcers. }\end{array}$ \\
\hline Arthritis & $\begin{array}{l}\text { Non erosive involing } 2 \text { or more } \\
\text { peripheral joints with tenderness } \\
\text { swelling, or effusion. }\end{array}$ \\
\hline Serositis & Pleuritis, or pericarditis. \\
\hline Renal & $\begin{array}{l}\text { Proteinuria greater than } 0.5 \mathrm{~g} / \text { day } \\
\text { or }>3+\text { dipstick, or cellular casts. }\end{array}$ \\
\hline Neurological & $\begin{array}{l}\text { Seizures or psychosis without other } \\
\text { Cause. }\end{array}$ \\
\hline Haematological & $\begin{array}{l}\text { Hemolytic anaemia, leukopenia, or } \\
\text { Thrombocytopenia. }\end{array}$ \\
\hline Autoantibodies & $\begin{array}{l}\text { Anti-ds DNA or anti-sm antibodies, } \\
\text { or false positive VDRL, abnormal level } \\
\text { of igM or IgG anticardiolipin } \\
\text { antibodies, or lupus anti-coagulant. }\end{array}$ \\
\hline ANA & Abnormally elevated ANA titers. \\
\hline
\end{tabular}

If four or more criteria are present at any time during disease course, SLE can be diagnosed with $75 \%$ specificity and $95 \%$ sensitivity.

During pregnancy lupus improves in third of women, remains unchanged in a third and worsens in the remaining. It is certain that lupus can be life threatening to both mother and the baby. One third of the women with lupus nephritis experience SLE exacerbation during pregnancy and 20\% experience renal deterioration. Active renal involvement is defined as the presence of active urine sediment and/or proteinuria $>0.5 \mathrm{~g} / \mathrm{dL}$ with or without an elevation in sr. creatinine ${ }^{1}$ by the American College of Rheumatology criteria. Up to $75 \%$ of SLE patients have clinically evident renal disease in pregnancy. The risk of developing preeclampsia is increased nearly 6 fold in women with SLE compared to controlled population. Other obstetric complications associated with SLE are increased foetal wastages, stillbirths, preterm delivery, and IUGR.

The reasons for adverse foetal consequences include decidual vasculopathy with placental infarction and decreased perfusion. Active nephritis is associated with significantly higher incidence of maternal complications. Low levels of compliments are more likely associated with active disease. Urine is tested frequently to detect new-onset or worsening of proteinuria. Persisting overt proteinuria is an ominous sign even more so if accompanied by nephrotic syndrome or abnormal sr. creatinine levels. The foetus should be closely observed for adverse effects. Anti-SSA (Ro) and anti-SSB (La) may damage the foetal heart and conduction system causing neonatal death. Congenital heart block results from diffuse myocarditis and fibrosis in the region between the AV node and bundle of His.

The main stay of treatment for SLE is corticosteroids. Prednisolone and methylprednisolone have minimal placental transfer and are the drugs of choice in pregnancy. The risk of developing hypertension and glucose intolerance during pregnancy is considerable with higher doses and calcium must be supplemented to compensate for bone marrow loss with chronic use of steroids. High dose of steroids during pregnancy is also associated with an increased risk of PROM, preterm labour, and IUGR. Anti-malarials such as hydroxychloroquine is useful for skin and joint symptoms. Levy and colleagues ${ }^{4}$ assigned 20 pregnant women to hydroxychloroquine and reported improvements in SLEPDAI scores with drug use. Discontinuation of hydroxychloroquine during pregnancy has been documented to increase the risk of lupus flare.

\section{CONCLUSION}

In General, Pregnancy outcome is Best if.

1. Lupus activity has been quiescent for at least 6 months before conception.

2. There is no active renal involvement manifest by proteinuria or renal dysfunction.

3. Superimposed preeclampsia does not develop.

4. There is no evidence of antiphospholipid antibody activity.

Our case was diagnosed as SLE in third trimester of pregnancy as it has six criterias of the American Rheumatism Association for SLE (malar rash, discoid rash, oral ulcers, renal involvement, autoantibodies, and ANA in elevated titres). Patient was in an active phase of nephritis with persisting 
nephrotic range of proteinuria, severe anaemia, and with severe skin lesions. In spite of the severity of the disease, the best maternal perinatal outcomes were obtained with active surveillance of both mother and the foetus.

\section{REFERENCES}

1. Stanhope TJ, White WM, Moder KG, et al. Obstetric nephrology: lupus and lupus nephritis in pregnancy. CJASN 2011;7(12):2089-99.
2. Hunong DL, Wechsler B, Vauthier-Brouzes D, et al. Pregnancy in past or present lupus nephritis: a study of 32 pregnancies from a single centre. Ann Rheum Dis 2001;60(6):599-604.

3. Wagner SJ, Craici I, Reed D, et al. Maternal and foetal outcome in pregnant patients with active lupus nephritis. Lupus 2009;18(4):342-7.

4. Levy RA, Vilela VS, Cataldo MJ, et al. Hydroxychloroquine (HCQ) in lupus pregnancy: double-blind and placebocontrolled study. Lupus 2001;10(6):401-4. 